\title{
DEFLECTION RESPONSE OF REINFORCED CONCRETE SLABS TESTED IN PUNCHING SHEAR IN FIRE
}

\author{
Holly K. M. Smith ${ }^{\text {ab }}$, Tim J. Stratford ${ }^{\mathrm{b}}$, Luke A. Bisby ${ }^{\mathrm{b}}$ \\ ${ }^{a}$ AECOM, 1 Tanfield, Edinburgh EH3 5DA, UK \\ ${ }^{\mathrm{b}}$ School of Engineering, The University of Edinburgh, The King's Buildings, Edinburgh, EH9 3JL, UK
}

\begin{abstract}
Flat slab-column punching shear specimens were tested under combined load and fire exposure, with varying edge restraint conditions. The slabs deflected away from the heat source (in the direction of loading) at all stages of the tests. This paper examines this unusual deflection behaviour, although no definitive reason for this unexpected behaviour has been found.
\end{abstract}

Keywords: punching shear, flat slab, fire, support conditions, deflection response

\section{INTRODUCTION}

The punching shear capacity of reinforced concrete slabs at elevated temperatures has been highlighted by Annerel et al., 2011, as dependent on restraint conditions. Complexity is introduced into the punching shear behaviour by restrained support conditions causing restrained thermal expansion leading to in-plane forces. There have been some experimental tests of punching shear in fire (Kordina, 1997, Annerel et al., 2011, Salem et al., 2012 and Ghoreishi et al., 2013), but none that has looked at restraint conditions.

This paper presents experimental results from three types of model slab-column specimens: ambient/simply supported, heated/simply supported and heated/fully restrained. Smith et al., 2014 reported how a purpose built reaction frame allowed the support conditions to be varied and key results. In this paper, we examine the deflection response at high temperature in more detail. During the tests, we noted that regardless of the support conditions, the slabs continuously deflected away from the heat source and in the direction of loading. This behaviour was also seen by Kordina, 1997 after 30 minutes of heating, in four initial (simply supported) tests.

\section{EXPERIMENTAL METHODOLOGY}

A series of fifteen slab-column specimens were constructed and tested in punching shear at both ambient and elevated temperature. The specimens had slab dimensions of $1400 \times 1400 \times$ varying thicknesses of 50, 75 and $100 \mathrm{~mm}$. The slabs were reinforced with $0,0.8 \%$ and $1.5 \%$ steel ratios and no shear reinforcement was provided. The orthogonal flexural reinforcement was based on the ambient design methods of Guandalini et al., 2009. The test methodology, regime and instrumentation are detailed in Smith et al., 2014.

The punching shear failure of a slab-column joint in a building (Fig. 1A) was inverted to allow the boundary support conditions of the specimens to be altered. Both unrestrained (Fig. 1B) and restrained (Fig. 1D) boundary support conditions were tested. Figures $1 \mathrm{C}$ and 1E show the inverted test orientation with load applied to the column stub and heat applied from above via an array of radiant heat panels. The restrained condition was achieved by resting the frame in contact with the slab (Fig. 1E). 
A

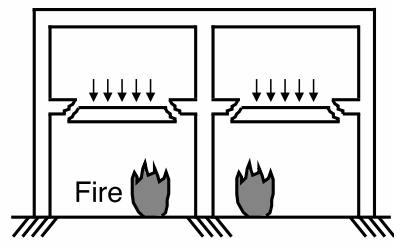

Structural situation

Inverted test setup

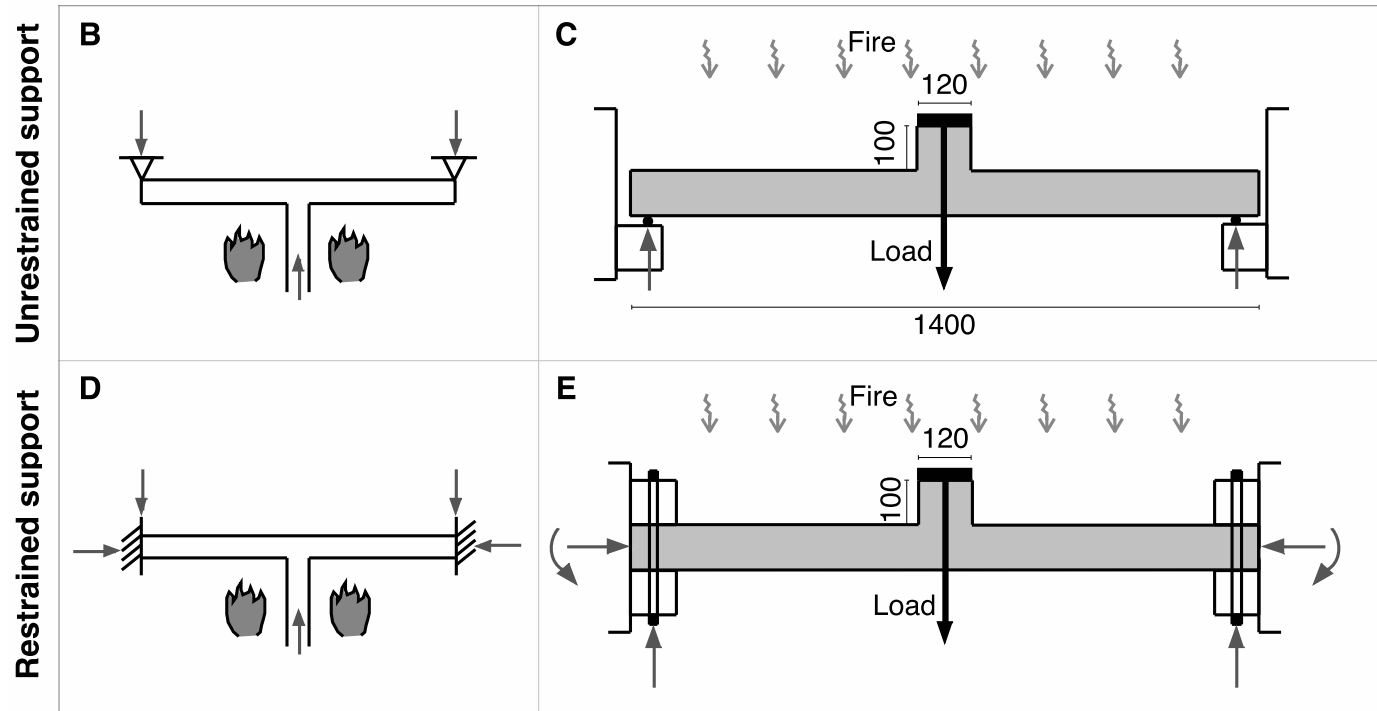

Fig. 1 A. Structural punching shear failure in fire, B.\&C. Unrestrained support, D.\&E. Restrained support, where B.\&D. Reaction forces in structural situation, C.\&E. Inverted test setup with reaction forces

Table 1 Slab-column test programme (where: $\mathrm{R}$ denotes residual capacity)

\begin{tabular}{|c|c|c|c|c|c|c|}
\hline $\begin{array}{l}\text { Specimen } \\
\text { ID }\end{array}$ & $\begin{array}{c}\text { Fire } \\
\text { Scenario }\end{array}$ & $\begin{array}{l}\text { Support } \\
\text { Condition }\end{array}$ & $\begin{array}{c}\text { Slab } \\
\text { Thickness } \\
(\mathrm{mm})\end{array}$ & $\begin{array}{c}\text { Steel } \\
\text { Ratio/Diameter } \\
(\%) /(\mathrm{mm})\end{array}$ & $\begin{array}{l}\text { Failure Load } \\
(\mathrm{kN})\end{array}$ & $\begin{array}{l}\text { Burn Time } \\
\quad(\min )\end{array}$ \\
\hline AU50-0.8 & \multirow{5}{*}{ Ambient } & \multirow{10}{*}{ Unrestrained } & 50 & $0.8 / 6$ & 54.2 & - \\
\hline AU75-0.8 & & & 75 & $0.8 / 6$ & 101.4 & - \\
\hline AU100-0 & & & 100 & $0 /-$ & 43.8 & - \\
\hline AU100-0.8 & & & 100 & $0.8 / 6$ & 226.3 & - \\
\hline AU100-1.5 & & & 100 & $1.5 / 8$ & 279.7 & - \\
\hline HU50-0.8 & \multirow{10}{*}{ Heated } & & 50 & $0.8 / 6$ & $55.7 \mathrm{R}$ & 120 \\
\hline HU75-0.8 & & & 75 & $0.8 / 6$ & $90.7 \mathrm{R}$ & 121 \\
\hline HU100-0 & & & 100 & $0 /-$ & 38.9 & 6 \\
\hline HU100-0.8 & & & 100 & $0.8 / 6$ & 174.8 & 4 \\
\hline HU100-1.5 & & & 100 & $1.5 / 8$ & 237.0 & 14 \\
\hline HR50-0.8 & & \multirow{5}{*}{ Restrained } & 50 & $0.8 / 6$ & $64.4 \mathrm{R}$ & 121 \\
\hline HR75-0.8 & & & 75 & $0.8 / 6$ & $115.5 \mathrm{R}$ & 120 \\
\hline HR100-0 & & & 100 & $0 /-$ & $82.2 \mathrm{R}$ & 99 \\
\hline HR100-0.8 & & & 100 & $0.8 / 6$ & $245.1 \mathrm{R}$ & 120 \\
\hline HR100-1.5 & & & 100 & $1.5 / 8$ & 233.2 & 105 \\
\hline
\end{tabular}

\section{EXPERIMENTAL RESULTS AND DISCUSSION}

This paper presents the key load capacities, slab temperatures, and vertical deflections. The experimental methodology has been validated to investigate the unexpected load-deflection 
behaviours in fire. A sensitivity analysis of the DIC displacement measurements and comparison to displacement transducer data at elevated temperature has been presented. Table 1 details the slabcolumn test programme and load capacities. HU50-0.8 and HU75-0.8 failed in flexure-shear mechanisms, whereas HR100-0.8 and HR100-1.5 failed in pure shear (Smith et al., 2014).

\subsection{Structural Reaction Frame Displacement}

The reaction frame columns were instrumented with strain gauges to measure the boundary reaction in-plane forces and moments. The lateral structural frame displacement was calculated using stiffness measurements undertaken by Fox, 2013. The strain gauge data was not conclusive, however a reading was used to give an upper bound to the horizontal frame displacement. The maximum and hence conservative, net average axial force was approx. $20.5 \mathrm{kN}$ on each column in the HR100-1.5 test. The maximum potential horizontal displacement in the tests could have been approx. $32 \mathrm{~mm}$. This proves that the restrained support condition was not perfectly fixed.

\subsection{Temperature Evolution}

The thermocouple data was compared between different tests to investigate if the radiant panels produced an even heating across the upper surface of the specimens. The positioning was measured post-failure to correct for potential casting errors. In each test, the temperature readings were similar at comparable slab depths, even at different thermocouple tree locations. The radiant array therefore produced an approximate even distribution of heating insult on the upper surface of each slab. Assuming the same boundary conditions at the upper and lower slab surface, allows the thermocouple data for different slab thicknesses to be compared. Figure 2 shows a large test variation in temperature curves at approx. the same slab depth. This proves that the fire scenario between different tests was not consistent, due to environmental impacts and gas supply differences/limitations (Smith et al., 2014). Both the $100 \mathrm{~mm}$ thick, reinforced, unrestrained slabs failed soon after ignition with ambient flexural reinforcement temperatures. The HR100-1.5 specimen failed 40 minutes into the cooling phase, with a maximum flexural steel temperature of approx. $148^{\circ} \mathrm{C}$. According to Eurocode 2, the steel had no strength reduction at this temperature.

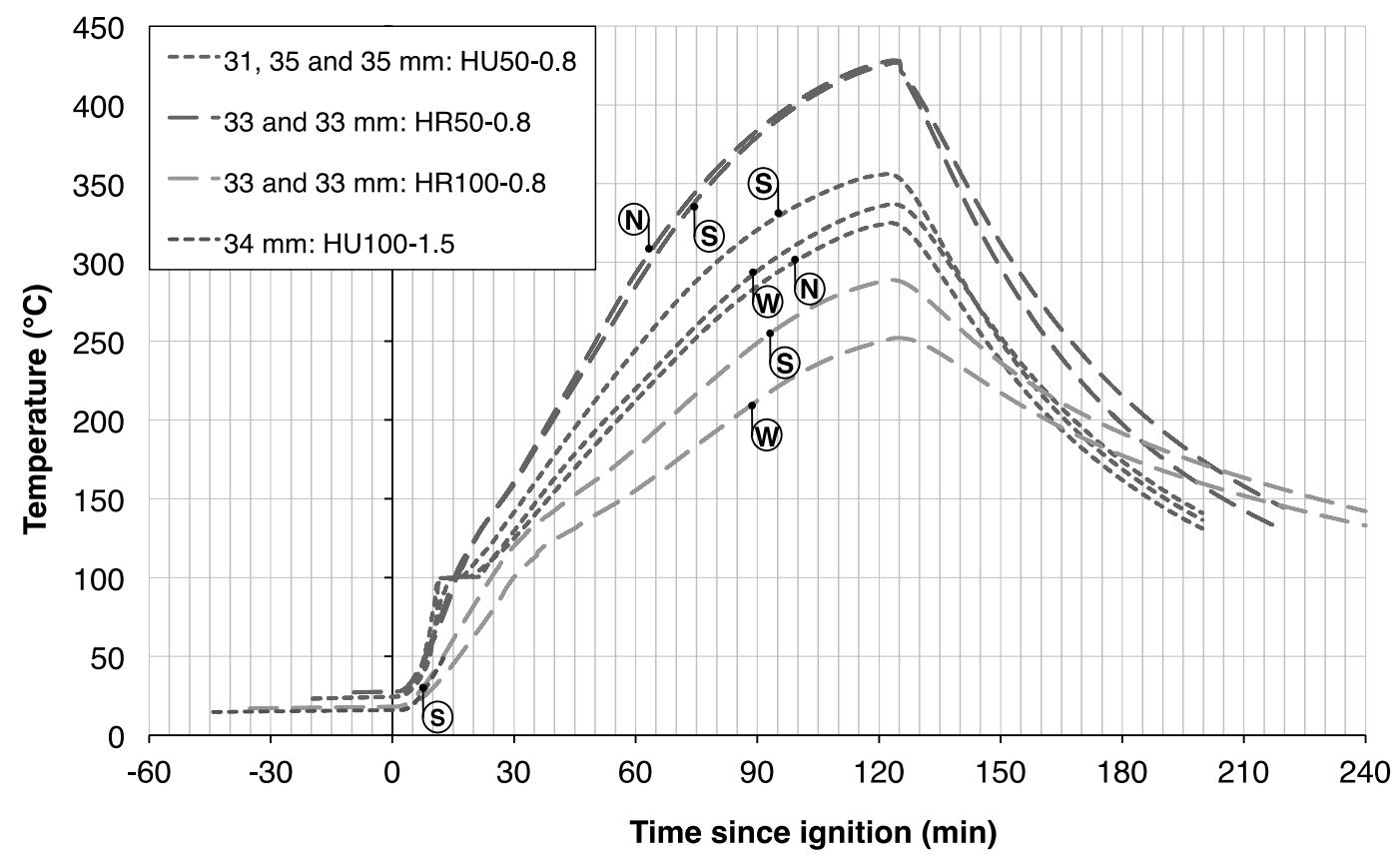

Fig. 2 Comparison of temperature curves for similar thermocouple depths in various tests

\subsection{Load-deflection Behaviour}

Figures $3 \mathrm{~A}$ and $\mathrm{B}$ show the load-deflection behaviour for the parameters $0.8 \%$ reinforcement ratio and $100 \mathrm{~mm}$ slab thickness, respectively. The deflection readings are measured by displacement 
transducer and have been corrected for initial concrete bedding in. Zero time corresponds to the start of heating, with the negative time region corresponding to loading of the slabs prior to ignition. Positive deflection is downwards, in the direction of loading and away from the heat source (see Fig. 1). During the heating phase the applied load was kept constant (70\% ambient capacity), however the central displacement of all of the slabs, irrespective of support condition, increased continually away from the heat source. As the cooling phase initiated, there was again a distinctive increase in the displacement rate, continuing to deflect away from the heat source. As the slabs reached $150^{\circ} \mathrm{C}$ throughout their thickness and prior to unloading the specimen, the displacement rate reached a constant level. With the exception of the lightly reinforced, $50 \mathrm{~mm}$ thick, unrestrained specimen (HU50-0.8), which as seen in Fig. 3A deflected toward the heat source at the end of the cooling phase.
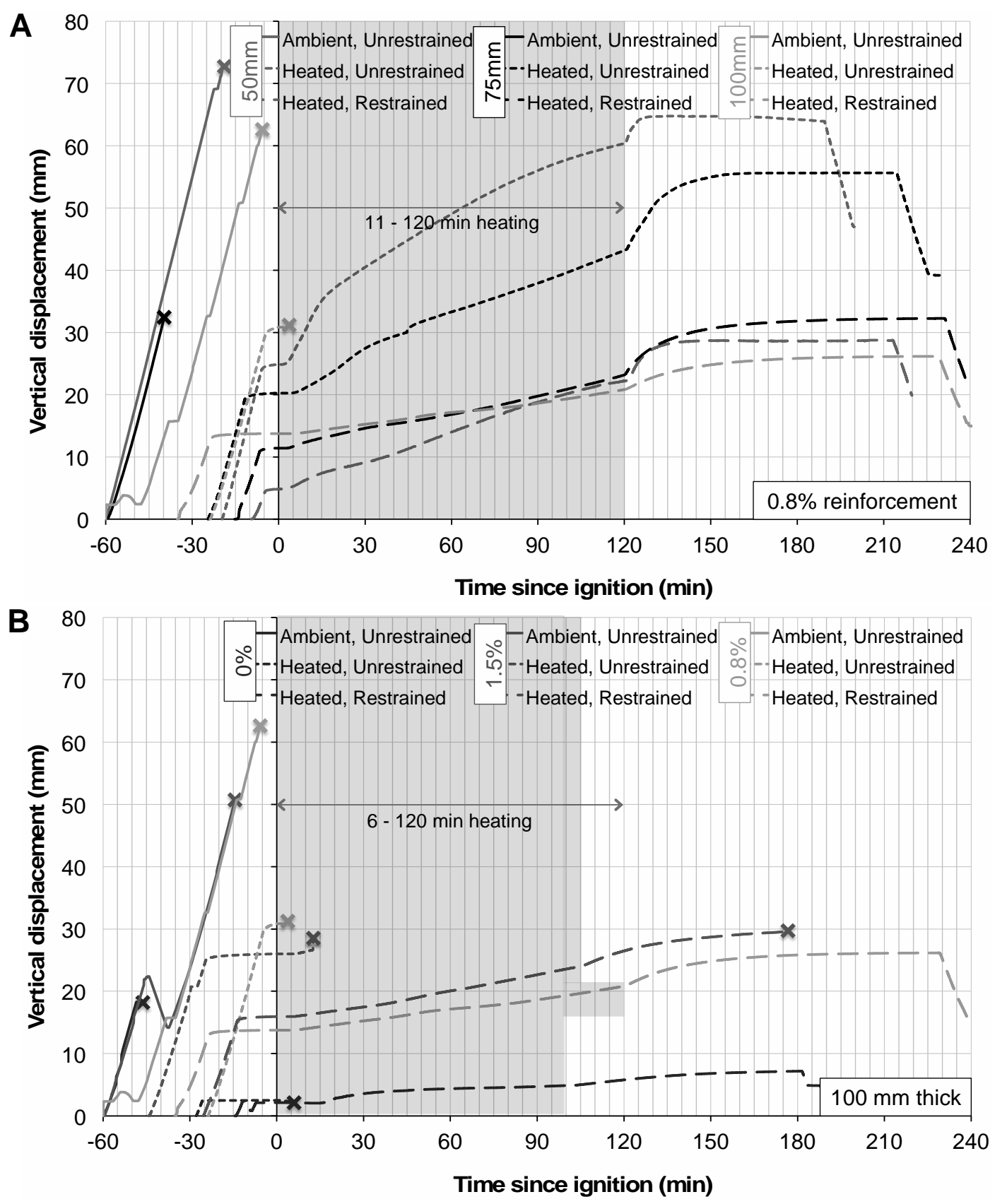

Fig. 3 Central vertical displacement history for the A. 0.8\% reinforced and B. $100 \mathrm{~mm}$ thick specimens

\subsection{Digital Image Correlation Deflection Response}

Vertical displacement was also measured by three digital SLR cameras (two Canon 650D and one 450D with $50 \mathrm{~mm}$ fixed focal length lenses), positioned out with the structural reaction frame, at 
angles to the lower (unheated) surface of the slab. A sensitivity analysis showed all three cameras measured similar deflections and axis symmetrical failures, which were confirmed by post-failure plan and cross-sectional photos. Figure 4 presents a comparison of the DIC central vertical displacement from one of the 650D cameras, to the displacement transducer readings for the heated, $100 \mathrm{~mm}$ thick specimens. The DIC readings show the same displacement behaviour as the transducers, however the DIC displacements are consistently less. There is a clear correlation in the percentage difference in displacement readings, however it is not consistent throughout the test. The displacement transducer readings must have been impacted by structural reaction frame movements, causing them to overestimate the central displacement.

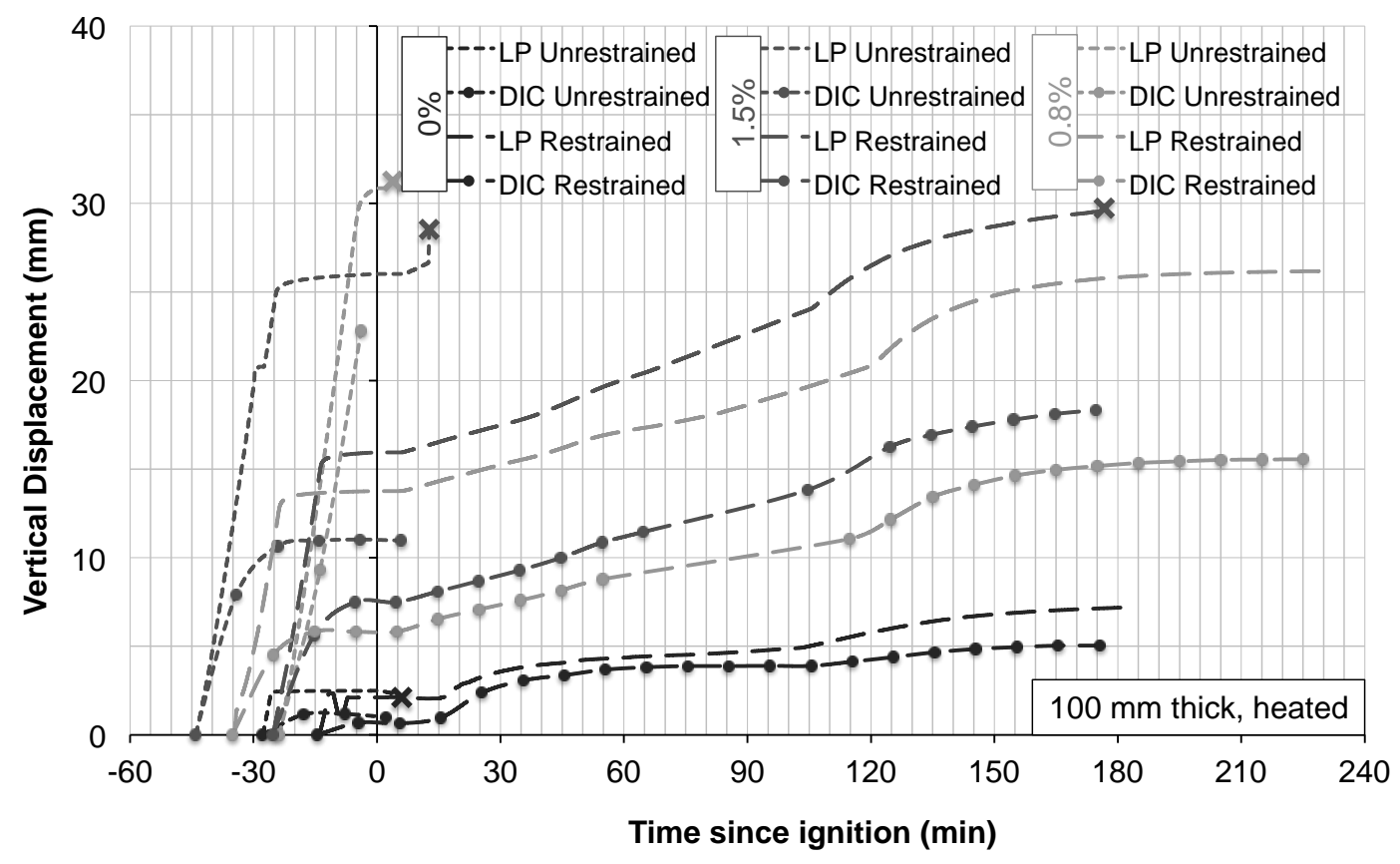

Fig. 4 Comparison of DIC and displacement transducer central vertical displacement history for the $100 \mathrm{~mm}$ thick, heated specimens

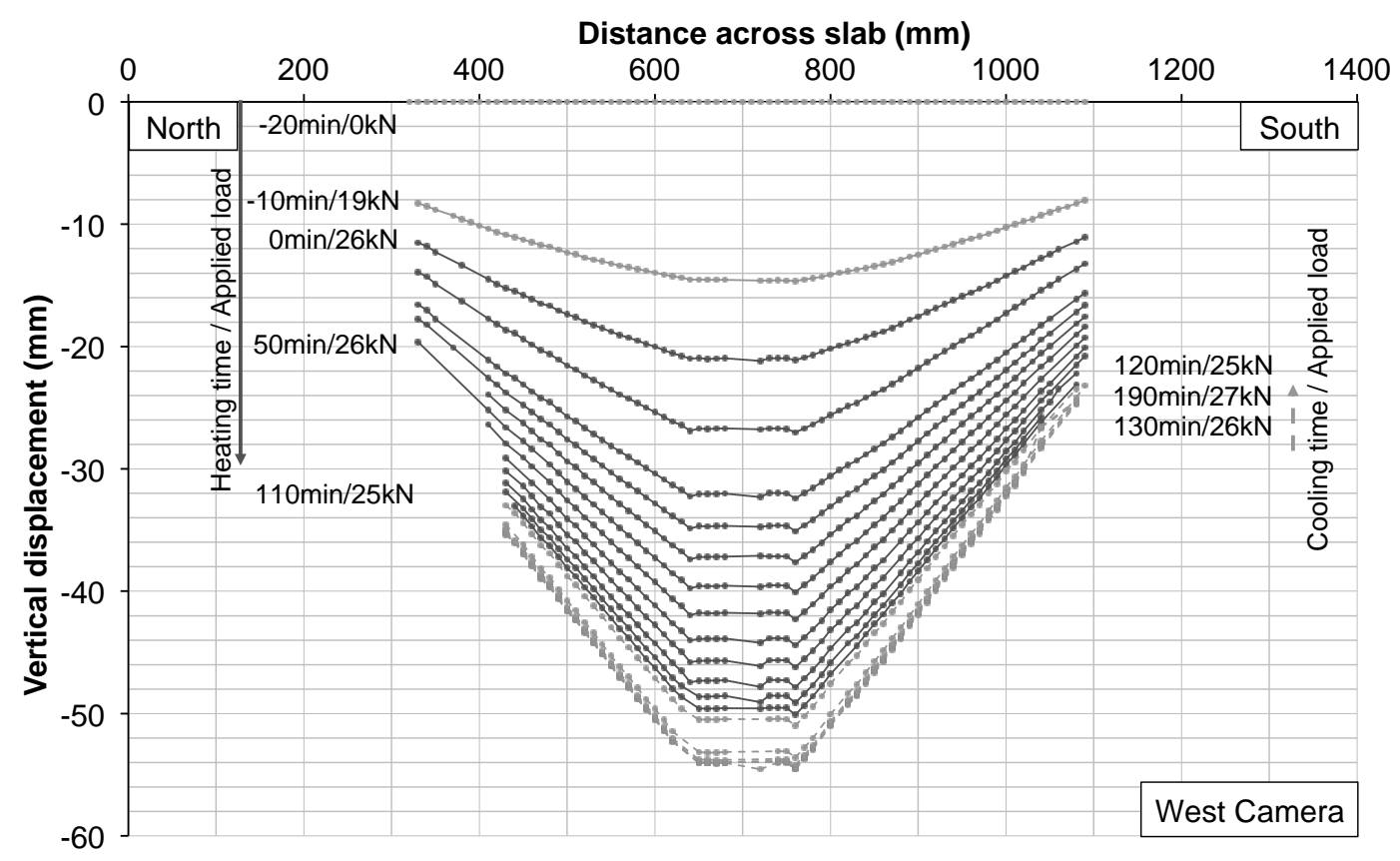

Fig. 5 DIC vertical displacement profile at 10 minute intervals for specimen HU50-0.8

Figure 5 shows the vertical DIC displacement profile across the $50 \mathrm{~mm}$ thick, $0.8 \%$ reinforced unrestrained slab at 10 minute intervals relative to ignition. Negative deflection is downwards, in the direction of loading and away from the heat source (see Fig. 1). DIC confirms that the central 
cross-sectional surface, for all the slabs, continually deflects away from the heat source, with a small approximate recovery of $1 \mathrm{~mm}$ towards the end of the HU50-0.8 cooling phase. A direct comparison of the central DIC displacement between the ambient and elevated temperature unrestrained tests (prior to residual testing) gives no clear trend in the thermally induced deflection (Table 2). The restrained support condition adds complexity, which cannot be explained with the experimental data recorded. A heat transfer analysis is required to evaluate what impact the support condition, heating and loading each have on the punching shear behaviour.

Table 2 DIC test end central displacement (prior to residual testing)

\begin{tabular}{|c|c|c|c|c|c|}
\hline \multirow{2}{*}{$\begin{array}{c}\text { Fire Scenario / Support } \\
\text { Condition }\end{array}$} & \multicolumn{5}{|c|}{ Slab Thickness (mm) - Reinforcement Ratio (\%) } \\
\cline { 2 - 6 } & $50-0.8$ & $75-0.8$ & $100-0$ & $100-0.8$ & $100-1.5$ \\
\hline $\mathrm{AU}$ & 63 & 26 & 12 & 24 & 28 \\
\hline $\mathrm{HU}$ & 53 & 45 & 1 & 61 & 21 \\
\hline $\mathrm{HR}$ & 28 & 23 & 5 & 15 & 27 \\
\hline
\end{tabular}

\section{CONCLUSIONS}

- Digital image correlation (DIC) has been used to accurately measure displacements in structural fire tests, even with the camera positioned at angles to the measurement plane.

- DIC shows the central displacement to increase under heating and cooling insult, with constant loading. Irrespective of support condition, the slab displaced continually away from the heat source, in the direction of loading. Only the HU50-0.8 specimen recovered approx. 1 mm during the cooling phase.

- The test setup has been assessed to investigate the unusual slab-column deflection away from the heat source (in the direction of loading); however, the complex behaviour observed during the tests cannot currently be explained, and more detailed modelling will be required.

\section{ACKNOWLEDGMENTS}

This PhD project was supported by funding from the EPSRC, together with additional follow-up funding provided by EPSRC and AECOM.

\section{REFERENCES}

Annerel E., Lu L., Taerwe L., 2011. Punching shear tests on flat concrete slabs at high temperatures, in 2nd International RILEM Workshop on Concrete Spalling due to Fire Exposure, 5-7 October 2011, Delft, The Netherlands, p. 125-131.

Eurocode 2. 2004. Design of Concrete Structures, Part 1-2: General Rules - Structural Fire Design. EN 1992-1-2.

Fox D., 2013. The Fire Performance of Restrained Polymer-Fibre-Reinforced Concrete Composite Slabs, $\mathrm{PhD}$ Thesis, The University of Edinburgh.

Ghoreishi M., Bagchi A., Sultan M.A. 2013. Review of the punching shear behaviour of concrete flat slabs in ambient and elevated temperature. Journal of Structural Fire Engineering, 4(4), p. 259-279.

Guandalini, S., Burdet, O., Muttoni, A. 2009. Punching tests of slabs with low reinforcement ratios. ACI Structural Journal, 106(10), p. 87-95.

Kordina, K. 1997. Über das Brandverhalten punktgestützter Stahlbetonplatten (On the Fire Behaviour of Reinforced Concrete Flat Slabs), Deutscher Ausschuss für Stahlbeton (DAfStb).

Salem H., Issa H., Gheith H., Farahat A., 2012. Punching shear strength of reinforced concrete flat slabs subjected to fire on their tension sides. Housing and Building National Research Center Journal, 8(1), p. $36-46$.

Smith, H.K.M., Stratford, T.J., Bisby, L.A., 2014. Punching shear of restrained reinforced concrete slabs under fire conditions, in $8^{\text {th }}$ International Conference on Structures in Fire, 11-13 June 2014, Shanghai, China, p. 443-450. 